\title{
Diortos
}

Revista de Comunicación Digital

\section{La acción conectiva de las mujeres. Análisis de la movilización del \#ParolnternacionalDeMujeres del 08 de marzo de 2017}

\section{Women's Connective Action. Analysis of the mobilization of the \#ParolnternacionalDeMujeres of March 8, 2017}

\author{
Rocío Annunziata \\ rocio.annunziata@gmail.com \\ Consejo Nacional de Investigaciones Científicas y Técnicas \\ Universidad Nacional de San Martín
}

\section{Resumen}

Este artículo presenta un análisis del modo de manifestarse y de las percepciones de las/ os participantes en el \#ParolnternacionalDeMujeres que tuvo lugar el 8 de marzo de 2017 en Argentina. Su hipótesis sostiene que la movilización mostró una lógica de acción conectiva híbrida. La investigación que sustenta este trabajo consistió en la realización de una encuesta en el momento y lugar de la movilización, a un total de 365 personas, con el propósito de capturar la percepción de las/os participantes y no simplemente de las/os impulsoras/es. Los datos resultantes de la encuesta se interpretaron considerando cinco dimensiones analíticas creadas a partir del concepto de acción conectiva: carácter individual o colectivo de la participación; grado de espontaneidad; rol de las redes sociales; percepción del carácter político de la movilización; rol de la negatividad. La conclusión del artículo sostiene que la movilización del 8M 2017 tuvo la fisonomía de una acción conectiva híbrida, en la medida en que se caracterizó por una presencia significativa de personas que participaron a modo individual o como ciudadanas/os independientes, que fueron co-creadoras activas del acontecimiento en las redes sociales y que otorgaron un rol preponderante al rechazo o la negatividad, mientras que el grado de espontaneidad de la movilización fue relativamente bajo y el reconocimiento del carácter político y trans-partidario de la misma fue alto.

\section{Palabras clave}

movilizaciones ciudadanas; redes sociales; acción conectiva; encuestas en protestas

Recibido: 16/12/2019 Aceptado: 04/04/2020

Cómo citar este artículo:

Annunziata, R. (2020). La acción conectiva de las mujeres. Análisis de la movilización del \#ParolnternacionalDeMujeres del 08 de marzo de 2017. Dígitos. Revista de Comunicación Digital, 6: 159-180. DOI: 10.7203/ rd.v1i6.177 


\begin{abstract}
This article presents an analysis of the way of manifesting and the perceptions of the participants in the \#ParolnternacionalDeMujeres that took place on March 8, 2017 in Argentina. Its hypothesis argues that the mobilization showed a logic of hybrid connective action. The research that supports this work consisted of conducting a survey at the time and place of the mobilization, to a total of 365 people, with the purpose of capturing the perception of the participants and not simply of the organizers. The data resulting from the survey were interpreted considering five analytical dimensions created from the concept of connective action: individual or collective nature of participation; degree of spontaneity; role of social networks; perception of the political nature of the mobilization; role of negativity. The conclusion of the article maintains that the mobilization of $8 \mathrm{M} 2017$ had the appearance of a hybrid connective action, insofar as it was characterized by a significant presence of people who participated individually or as independent citizens, who were active co-creators in the event on social networks and that gave a predominant role to rejection or negativity, while the degree of spontaneity of the mobilization was relatively low and the recognition of its political and trans-partisan character was high.
\end{abstract}

\title{
Keywords
}

citizen mobilizations; social networks; connective action; \#ParolnternacionalDeMujeres; surveys in protest

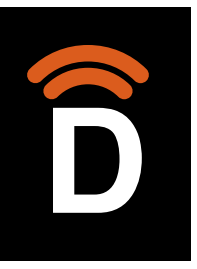

La acción conectiva de las mujeres. Análisis de la movilización del \#ParolnternacionalDeMujeres del 08 de marzo de 2017

\section{Introducción}

El 8 de marzo de 2017, fecha en la que se conmemora el Día Internacional de la Mujer Trabajadora, tuvo lugar en Argentina y en más de 50 países del mundo la movilización por el \#ParolnternacionalDeMujeres. En la Ciudad de Buenos Aires llegó a reunir 250.000 personas y también se desplegó en otras ciudades del país. Esta movilización tuvo como antecedentes directos al "Paro de Mujeres" o "Miércoles Negro" del 19 de octubre de 2016, y la inmensa movilización con la consigna \#NiUnaMenos del 3 de junio de 2015 que se había repetido también al cumplirse un año en junio de 20161 .

Fue la primera movilización \#NiUnaMenos de 2015 la que logró instalar el problema de la violencia contra las mujeres y de las desigualdades de género en la agenda pública y política como nunca antes en el país. Esta movilización, surgida puntualmente en Twitter, se transformó en un punto de confluencia de muchas organizaciones y colectivos de

1. La conmemoración del Día Internacional de las Mujeres el 8 de marzo ha sido hace tiempo una fecha clave del movimiento feminista, en particular desde fines de los años sesenta en los países del norte en el marco de la llamada "segunda ola" del feminismo, y en los países latinoamericanos desde el retorno de las democracias en los ochenta (Laudano, 2018). La novedad del 8M de 2017 fue la convocatoria a un "paro" de mujeres y la organización internacional mediada por las redes sociales y medios digitales. Los antecedentes más directos del paro de mujeres como tal habían sido el del 03/10/2016 en Polonia en contra de la criminalización del aborto y el del 19/10/2016 en Argentina en respuesta a un nuevo femicidio, que en pocos días había conseguido el apoyo de 22 países (Gago, 2018). Este último fue el primer paro de mujeres de la historia de Argentina y América Latina; constituyó un hito que conectó las violencias machistas con las violencias económicas y sociales del capitalismo, la explotación y la precarización laboral (Ni Una Menos, 2017b). 
mujeres, pero también alcanzó a gran parte de la sociedad que no se vinculaba con el activismo feminista. De hecho, esta primera movilización tuvo poco de estrictamente feminista, pero a medida que se fueron sucediendo nuevos acontecimientos como los mencionados, la orientación hacia consignas más feministas clásicas se fue consolidando. En 2017, el \#ParoDeMujeres, también conocido como 8M, fue promovido por colectivos feministas y de género de distintos lugares del mundo, entre los cuales el colectivo \#NiUnaMenos en Argentina tuvo un gran protagonismo. El Ilamamiento había sido lanzado por un grupo impulsor que reunía a mujeres polacas y latinoamericanas a través de un evento de Facebook y del sitio web del Paro Internacional de Mujeres (PIM) (Laudano, 2018). El 23 de enero de 2017 se difundió en Argentina, y el colectivo Ni Una Menos lo retomó con el lema \#NosotrasParamos \#NosMueveEIDeseo (Ni Una Menos, 2017a). Entre el día del llamamiento y la movilización innumerables organizaciones realizaron asambleas y encuentros preparatorios, y se produjo una fuerte discusión con los sindicatos (Gago, 2018). Para el 8M se convocó a un paro de actividades laborales y de cuidado, a un "ruidazo" y una movilización a la Plaza de Mayo que reunió una columna de manifestantes de 15 cuadras. Las redes sociales tuvieron un rol clave en la convocatoria y como ámbito de artivismo (Laudano, 2018; Fernández Rincón, 2019).

El objetivo del presente trabajo es analizar la perspectiva de las/os participantes en la movilización del 8M de 2017 en la Ciudad de Buenos Aires, Argentina, para comprender las características de las/os manifestantes, sus percepciones sobre su participación, el rol de las redes sociales en la misma, el carácter individual o colectivo, el carácter político o a-político, el papel de la negatividad y el grado de espontaneidad de la movilización. En investigaciones anteriores (Annunziata et al. 2016; Annunziata y Gold, 2018; Annunziata, 2019) hemos abordado la movilización \#NiUnaMenos del 3j de 2015 a partir de entrevistas en profundidad con las impulsoras y focalizándonos, por lo tanto, en el discurso y la interpretación de las mismas sobre el rol de las redes, la organización, la interacción entre lo online y lo offline y los sentidos de la convocatoria. En esta oportunidad buscamos, en cambio, estudiar la perspectiva de las/os participantes, a través de la realización de una encuesta en el momento y lugar de la protesta. Quienes se manifestaron, ¿lo hicieron como parte de un colectivo? ¿Con quién asistieron a la protesta? ¿Con cuánta antelación se enteraron? ¿Qué rol les asignaban a las redes sociales en la movilización? En definitiva: ¿puede decirse que se trató según su perspectiva de una experiencia de acción conectiva? Este artículo aspira a responder estas preguntas ofreciendo la información relevada el 8M de 2017.

En Argentina no disponemos de muchas investigaciones que capturen datos de las/ os participantes en movilizaciones en el momento mismo de las protestas. En este sentido, el artículo se propone realizar una doble contribución. Por un lado, aspira a hacer un aporte a la compresión del movimiento de mujeres en un momento puntual del ciclo de movilización y a observar el papel de las redes sociales y de la lógica de la acción conectiva en el movimiento. Por otro lado, busca aportar conocimiento sobre las formas de movilización contemporánea mediante una metodología que permite rastrear las motivaciones e interpretaciones de las/os participantes.

\section{La acción conectiva}

El siglo XXI nos ha obligado a repensar y re-conceptualizar los movimientos sociales y la acción colectiva a partir de las experiencias que comenzaron a surgir en distintas 
partes del planeta. Transformaciones tanto políticas como tecnológicas generaron que actualmente veamos desarrollarse formas de movilización y subjetividades políticas distintas a las que la literatura estaba habituada a enmarcar con las categorías de "acción colectiva" y "movimientos sociales". La denominada "Primavera Árabe", los Indignados en España, los movimientos Occupy en Estados Unidos, Canadá y otros lugares del mundo, el Movimiento \#YoSoy132 en México, las "Jornadas de Junio" de 2013 en Brasil, los movimientos estudiantiles en Chile, el \#NiUnaMenos en Argentina, se cuentan entre las experiencias que produjeron una forma particular de confluencia entre medios digitales y movilizaciones callejeras, invitando a la comunidad académica a interrogarse sobre la especificidad de los movimientos ciudadanos contemporáneos.

Muchos trabajos recientes se han centrado en analizar los efectos que las nuevas tecnologías tienen sobre las manifestaciones, agrupándose en quienes advierten efectos "fuertes" o "determinantes" frente a quienes se inclinan por efectos "débiles" o "no determinantes" (Welp, 2015), así como en quienes participan de una perspectiva "optimista" sobre dichos efectos frente a quienes se inscriben en un enfoque "pesimista", coincidiendo la mayoría, no obstante, en un predominio de la visión "tecno-determinista" que no reconoce la interdependencia entre las transformaciones tecnológicas y sociales sino que piensa los efectos de manera unidireccional (Annunziata y Gold, 2018)2.

En la numerosa producción actual sobre este fenómeno, sobresalen los aportes de Manuel Castells (2012) que han destacado la emergencia de una nueva forma de comunicación en el contexto del auge de los medios digitales y las redes sociales. El autor propone el concepto de "auto-comunicación de masas" para enfatizar el hecho de que cada ciudadano se ha convertido en un medio y es capaz de crear acontecimientos públicos. Los movimientos ciudadanos del S. XXI, para el autor, constituyen redes horizontales de comunicación interactiva y multidimensional. Pueden ser convocados por activistas que no están organizados previamente y tienden a ser espontáneos, lo que implica que se vuelve menos importante quién hace la convocatoria que cómo se multiplica. Suelen desconfiar de las formas de representación, liderazgo y delegación del poder, abrazando en cambio la horizontalidad y la expresión individual de causas colectivas.

Otro autor que ha hecho una contribución fundamental para el estudio de los nuevos movimientos ciudadanos en el marco de su teoría de la democracia es Pierre Rosanvallon $(2007,2012)$ quien ha advertido la preeminencia de la "negatividad" y de la "singularidad" en la política contemporánea. Por un lado, en el mundo político desideologizado de nuestro presente se ha vuelto mucho más fácil formar mayorías de reacción que mayorías de acción: el rechazo es preferido al proyecto, en la medida en que el primero muestra resultados inmediatamente eficaces y cumple plenamente su objetivo, mientras que el segundo no lo hace. Una gran variedad de motivos heterogéneos puede ser reunida por la negatividad porque además los rechazos pueden agregarse fácilmente, son idénticos entre sí. Rosanvallon (2007) habla entonces de un "pueblo-veto" para nombrar esta tendencia creciente a la expresión ciudadana negativa. Por otro lado, el autor sostiene que nos encontramos en sociedades de la singularidad, en las que los

2. Entre los que atribuyen a los medios digitales efectos fuertes o sostienen un enfoque optimista podemos mencionar a Ghonim (2013) y a Castells (2012); entre los que se inclinan por los efectos débiles, viendo en ellos sólo nuevos dispositivos en los que tienen lugar los fenómenos o prácticas políticas tradicionales, o que subrayan incluso efectos nocivos, cabe citar a Diani (2011), Weyland (2012), Welp (2015), o Waisbord (2015). 
individuos aspiran a ser considerados como personas únicas, a que se reconozcan sus anhelos y necesidades específicas y a poder auto-expresarse (Rosanvallon, 2012).

Lance Bennet y Alexandra Segerberg $(2012,2013)$ han desarrollado una de las perspectivas que creemos más fructíferas para comprender los nuevos movimientos ciudadanos en la intersección entre los medios digitales y las formas contemporáneas de protesta, sin caer al mismo tiempo en el tecno-determinismo. Para los autores, muchas de las movilizaciones recientes son mejor concebidas en términos de "acción conectiva" que en los términos clásicos de la "acción colectiva". La "acción colectiva" es el resultado de organizaciones con recursos, capaces de ofrecer sanciones, incentivos o identidades compartidas a sus miembros para motivarlos a participar. Los medios, incluso los medios digitales, son usados para transmitir mensajes que los organizadores buscan controlar y direccionar. Si bien este tipo de lógica sigue vigente en algunos casos, convive con un crecimiento de la lógica de la "acción conectiva", en la cual los medios digitales ya no se encuentran en el lugar de los canales de difusión, sino que colaboran en la creación de los acontecimientos y los sujetos, en la medida en que la comunicación se vuelve el principio organizativo mismo. La acción conectiva puede tratar sobre los mismos temas que la acción colectiva o los movimientos sociales clásicos, pero constituye un tipo de acción más personalizada, que ofrece a los manifestantes la posibilidad de expresarse a su propio modo; participar de un acontecimiento colectivo es una forma de expresión personal. La acción conectiva no requiere de identidades colectivas estables ni de altos niveles de recursos organizacionales ${ }^{3}$. Bennet y Segerberg (2012) distinguen, a su vez, dos tipos de acción conectiva: en el primero, que representa el tipo polarmente opuesto a la acción colectiva y cuyos ejemplos emblemáticos serían las experiencias de Occupy o Indignados, no existe ninguna organización que organice la acción, sino que son los propios medios digitales los que cumplen la función de principio organizativo; el segundo tipo de acción conectiva manifiesta un patrón híbrido, en el que puede haber organizaciones que impulsan, pero convocando a formas de participación y expresión personalizadas, de modo que no controlan del todo ni quiénes participan ni el mensaje que se transmite con la movilización. Para los autores, pueden darse ciclos en los que la acción se vaya moviendo de un tipo al otro.

A partir de estas contribuciones teóricas, proponemos extraer una serie de indicadores para analizar las movilizaciones. Cuanto más se acerquen al polo puro de la acción conectiva esperaremos que:

a) las/os participantes no concurran como miembros de un colectivo o una organización;

b) las protestas sean más espontáneas, es decir, no sea muy importante quién las organiza y las/os participantes hayan conocido la convocatoria con poca anticipación;

c) las redes sociales sean la principal fuente de difusión y las/os participantes no sean meros asistentes sino también creadores del acontecimiento en las redes sociales;

\footnotetext{
3. Así como no resulta suficiente la categoría clásica de "acción colectiva", creemos que tampoco alcanza para comprender los fenómenos contemporáneos la categoría de "movimientos sociales", puesto que, si bien existe una amplísima variedad de teorías y definiciones (Diani, 2015), esta categoría pareciera exigir la presencia de al menos tres elementos en un "movimiento social": identidad, organización e ideología compartida.
} 
d) las/os participantes consideren a la manifestación como a-política;

e) la negatividad sea predominante.

En Argentina esta lógica de la acción conectiva puede contribuir a la interpretación de varias movilizaciones recientes, entre las que sobresale sin dudas por su impacto en el escenario nacional la movilización del 3 de junio de 2015 conocida como \#NiUnaMenos (Annunziata y Gold, 2018)4. La misma reunió más de 200.000 manifestantes en la Ciudad de Buenos Aires y muchos miles en otras ciudades del país, y se convirtió en trending topic mundial el día de la protesta (Annunziata et al., 2016). Esta movilización surgió en las redes sociales, ante la noticia de un nuevo caso de femicidio, impulsada por un grupo de periodistas y comunicadoras que no conformaban una organización y algunas de las cuales nunca se habían encontrado personalmente (Rodríguez, 2015). Aunque existían organizaciones muy importantes que venían trabajando en el campo de los derechos de las mujeres y en contra de la violencia machista, como la Casa del Encuentro o la Campaña Nacional por el Derecho al Aborto Legal, Seguro y Gratuito, resulta difícil considerar al 3J 2015 como una expresión del movimiento feminista. De hecho, se decidió atenuar el contenido más propio de las demandas feministas, sobre todo en torno a la legalización del aborto (Natalucci y Rey, 2018). Las impulsoras iniciales del \#NiUnaMenos del 3J convocaron en torno a la consigna "Basta de femicidios", una consigna esencialmente negativa que fue clave en lograr la masividad de la convocatoria, en la medida en que pudo reunir a quienes rechazaban la muerte de adolescentes y se preocupaban sobre todo por la seguridad, con quienes consideraban que los femicidios constituyen un eslabón final de las varias formas de violencia machista que se ejerce contra las mujeres. Aunque se estableció un documento de cinco puntos con demandas concretas que se leyó en el acto central de la movilización, la negatividad de la consigna fue estructurante del acontecimiento y en particular de su masividad.

En definitiva, las impulsoras iniciales de la movilización no podrían ser concebidas estrictamente como "organizadoras" de la misma: no controlaban quién participaba, cómo se apropiaban distintas personas y grupos de la consigna y qué significación pública resultaría (Annunziata et al., 2016). Ellas mismas no eran una organización. Y, si bien en la movilización participaron muchos actores sí organizados (colectivos de mujeres, multisectoriales, espacios culturales e incluso sectores sindicales y partidarios que tenían una existencia y labor continua en la lucha por la igualdad de género) es aún menos posible sostener que estos grupos "organizaron" la movilización. En la práctica, las acciones surgidas de convocatorias más institucionales en este terreno no lograban reunir más que unas pocas personas.

El movimiento ciudadano que el 3J permitió salir a la luz fue un sujeto nuevo. Antes de la manifestación, "\#NiUnaMenos" era sobre todo una consigna, pero, luego del 3], comenzó a ser el nombre de un colectivo y a constituir un sujeto político. Zeifer (2017) ha analizado el modo en que el hashtag como género discursivo contribuyó a la consolidación de esta nueva subjetividad.

En efecto, a un año de la convocatoria, el 3 de junio de 2016, volvía a realizarse una manifestación masiva en Argentina. El 19 de octubre de ese mismo año se convocó

4. La transformación hacia la acción conectiva del movimiento de mujeres también ha sido observada en otros contextos. Kowalska (2018) considera que la "cuarta ola" del feminismo norteamericano se caracteriza precisamente por el activismo mediado las redes sociales (social media). Trott (2018) analiza distintas experiencias australianas recientes (2018) mostrando cómo pueden interpretarse con la lógica de la acción conectiva, y agregando la importancia de las redes interpersonales, en particular de amistad, para profundizar este enfoque en el caso de los movimientos de mujeres o feministas. 
al primer Paro de Mujeres, conocido como "miércoles negro". El 8 de marzo de 2017 se organizó el Primer Paro Internacional de Mujeres con la participación de más de 50 países. A medida que nuevas movilizaciones se sucedieron, se fue consolidando un movimiento y se fueron agregando demandas vinculadas a las desigualdades económicas y laborales, así como el reclamo por la legalización de la interrupción voluntaria del embarazo (Natalucci y Rey, 2018). Al mismo tiempo que el movimiento adquirió continuidad se fue orientando a una identidad más feminista ${ }^{5}$. El impacto del movimiento de mujeres en Argentina a partir de la gran movilización de 2015 condujo a que, en 2018, cuando la Campaña Nacional por el Aborto Legal, Seguro y Gratuito presentara por sétima vez un proyecto de ley al Congreso, el Presidente Mauricio Macri decidiera habilitar la discusión legislativa; en jornadas signadas por masivas movilizaciones y vigilias frente al Congreso, el proyecto recibió su aprobación en la Cámara de Diputados, pero fue rechazo por el Senado.

En este trabajo nos preguntamos si el ParolnternacionalDeMujeres del 8 de marzo de 2017 fue una expresión de acción conectiva. A diferencia del 3j de 2015, que se acercó más al polo de la acción conectiva pura, pareciera que la experiencia del 8M de 2017 puede concebirse como una acción conectiva híbrida en la que, si bien hay organizaciones que realizan la convocatoria, las/os participantes no tienden a concurrir como miembros de una organización y las redes sociales juegan un papel central en la difusión y creación del acontecimiento, permitiendo también la expresión personalizada de una causa colectiva.

\section{Metodología}

Este trabajo se apoya en los datos obtenidos a través de una encuesta que se efectuó el 8 de marzo de 2017 en la Ciudad de Buenos Aires. Para la realización de la encuesta se conformó un equipo de 35 encuestadoras/es y 6 coordinadoras/es ${ }^{6}$. Se encuestaron 365 personas, sobre una movilización que convocó $250.000^{7}$, de modo que la muestra se consideró suficientemente representativa.

Con el objetivo de generar una muestra en la que cualquier manifestante tuviera la misma probabilidad de ser encuestada/o, las/os encuestadores se distribuyeron por el espacio de manera de abarcar toda la zona entre el punto de partida y de llegada de la movilización, entre la Plaza de los Dos Congresos y la Plaza de Mayo, y de poder realizar la encuesta durante el tiempo de mayor asistencia, entre las 17 y las 20 horas. Si bien hubo movilizaciones en simultáneo en más de 60 ciudades en el país, la encuesta fue realizada solamente en la Ciudad de Buenos Aires (y las conclusiones se circunscriben a este ámbito). Cada coordinadora/or de grupo tomó un área de la movilización e indicó a las/os encuestadoras/es a quién dirigirse, considerando tanto a quienes marchaban al interior de una columna con banderas bien distinguibles como a quienes parecían marchar solas/os o en grupos pequeños sin identificación alguna de su pertenencia.

5. El movimiento feminista argentino tiene una inmensa trayectoria $y$, por supuesto, no surgió el 3j de 2015; en esa ocasión sí se produjo una acción conectiva de magnitudes inéditas que excedió al feminismo como movimiento social clásico y a su acción colectiva. En este trabajo proponemos pensar al 8M de 2017 como parte de este ciclo de acción conectiva, que, no obstante, se fue hibridizando con el transcurso del tiempo.

6. Agradezco al equipo de encuestadoras/es y especialmente las/os coordinadoras/es que me acompañaron: Valeria March, Juan Martín Galeano, Tomás Gold, Sol Wolgast y Bárbara Zeifer. También agradezco las valiosas recomendaciones de Julieta Lenarduzzi en distintas etapas de esta investigación.

7. Ver, por ejemplo, Iglesias (2017). 
La administración del cuestionario tuvo una duración aproximada de 15 minutos por persona. Las/os encuestadoras/es administraron el total del formulario de forma presencial y estuvo diseñado de modo tal que no fuera necesario girar una página y se pudiera continuar la caminata mientras se respondía.

Existen antecedentes de encuestas en protestas con una metodología similar que forman parte de un proyecto internacional y que también aseguran la similar probabilidad de los participantes de ser encuestados mediante la distribución espacial de los encuestadores (Stekelenburg et al., 2012; Klandermans, van Stekelenburg, y Walgrave, 2014). La distribución en el espacio varía según se trate de movilizaciones que van avanzando por una avenida principal o movilizaciones estáticas en plazas o parques. En el caso de esta investigación, la movilización combinó ambas características ya que se confluyó en Plaza de Mayo y había manifestantes en movimiento y avanzando por todas las calles que desembocan en ella. Somma, Rossi y Donoso (2019), que han aplicado la misma metodología de encuestas en protestas para casos latinoamericanos, destacan la ventaja de este tipo de encuestas para enfrentar los sesgos de memoria puesto que el relevamiento se realiza en el momento mismo de la manifestación.

Sin embargo, las investigaciones que han utilizado la metodología de encuestas en protestas seleccionan movilizaciones que son relativamente regulares, como las del Día del Trabajador o las Marchas del Orgullo Gay. Esta investigación, en cambio, se inscribe en un proyecto que aspira a capturar fenómenos de protesta más espontáneos, cuyas fechas se conocen con poca anticipación, con un formulario corto y enfocado más en el formato de la movilización que en el contenido de las consignas o tema de la protesta ${ }^{8}$. Este aspecto de la presente investigación agrega una justificación metodológica adicional a la recolección de información durante las protestas mismas con un cuestionario rápidamente adaptable al contexto9.

\section{El \#ParolnternacionalDeMujeres de 2017}

\subsection{Perfil de las/os participantes}

En este apartado nos proponemos brindar una primera información descriptiva sobre quiénes fueron las/os participantes del 8M de 2017. Quizá no resulte sorprendente el amplio predominio de las mujeres entre las/os manifestantes. Como vemos a continuación en el Gráfico 1, las mujeres fueron el 74\% de las encuestadas. El predominio de jóvenes entre las/os asistentes a la movilización fue muy marcado: la edad promedio de las/os participantes fue 35 años (con un desvío estándar de 15,68).

Si bien la mayoría de las/os manifestantes fueron de la Ciudad Autónoma de Buenos Aires, una cantidad significativa de personas se movilizó desde otras localidades para asistir a la protesta. Como vemos en el Gráfico 2, se acercaron mayormente residentes del Gran Buenos Aires (en este conjunto no hemos considerado a CABA) ${ }^{10}$ y de la

8. Aunque el 8M tuviera mucha organización previa, en este trabajo nos interesó observar la perspectiva de las/os manifestantes sobre la espontaneidad.

9. El proyecto prevé la realización de nuevas encuestas en protestas con el mismo cuestionario para poder producir posteriormente comparaciones sobre movilizaciones en torno a temas diferentes.

10. El Gran Buenos Aires es el área urbana o mega ciudad que comprende la Ciudad Autónoma de Buenos Aires y su conurbano sobre la Provincia de Buenos Aires, sin constituir una unidad administrativa. El INDEC considera que el Gran Buenos Aires está conformado por la Ciudad de Buenos Aires y los 24 partidos completos que la rodean, alcanzando una población de 12.806 .866 habitantes (2.890.151 en 


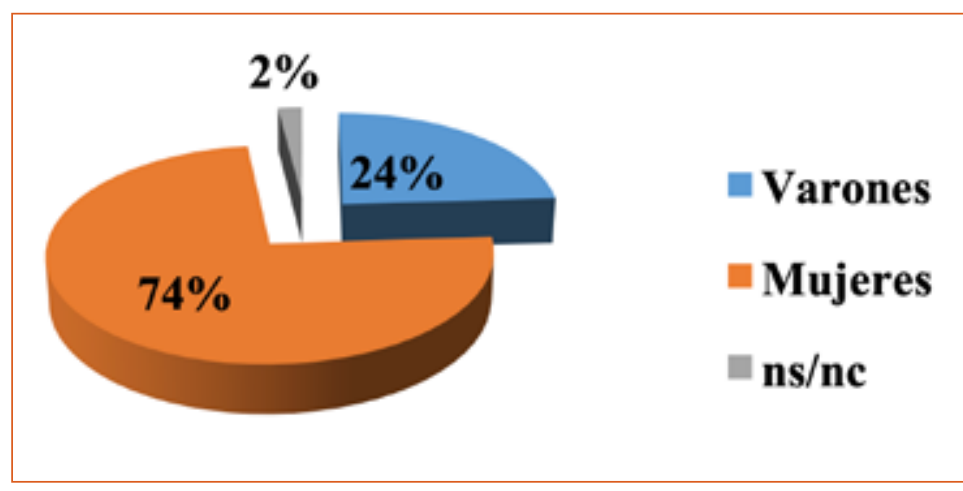

Gráfico 1. Porcentajes de mujeres y varones entre las/os manifestantes. Fuente: Elaboración propia

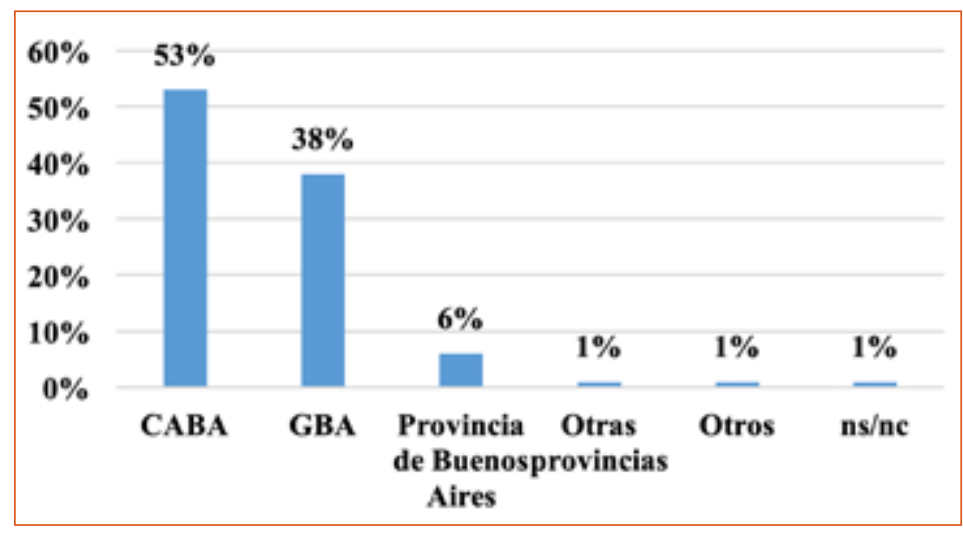

Gráfico 2. Lugar de residencia de las/os

manifestantes. Fuente: Elaboración propia

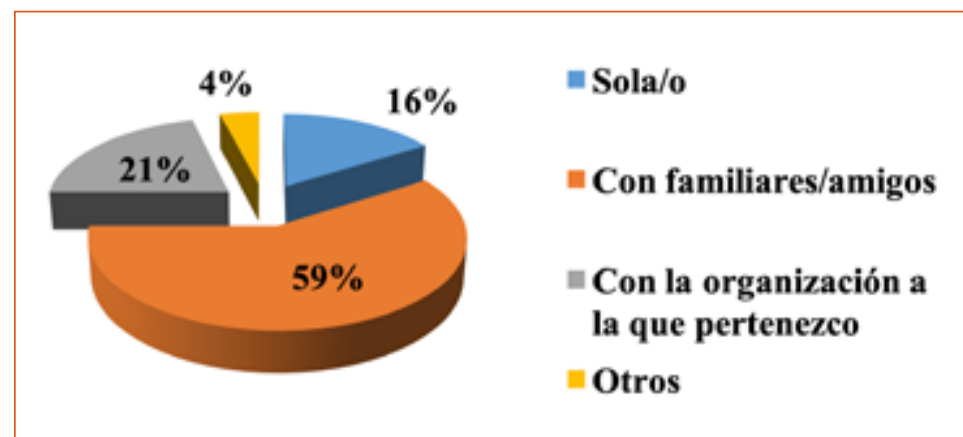

Gráfico 3. Con quiénes asistieron a la manifestación. Fuente: elaboración propia
Provincia de Buenos Aires, aunque también hubo una presencia minoritaria de residentes de otras provincias argentinas y de otros países. En cuanto a la ocupación, un $38 \%$ respondieron ser empleadas/ os y un $25 \%$ estudiantes (siendo el resto distribuido en categorías con proporciones menores, como cuentapropistas, desocupadas/os, jubiladas/os, profesionales, etc). Sobre el nivel de estudios, llama la atención la gran proporción de manifestantes con estudios terciarios o superiores: un $75 \%$ de las/encuestadas/os.

\subsection{Organización e identidad}

A pesar de la significativa presencia de banderas y columnas de organizaciones en la manifestación, la mayoría de los/as participantes respondió que estaba asistiendo a la protesta sola/o o con familiares o amigos (el 75\%). Sólo el $21 \%$ de las/ os encuestadas/os se movilizó con su organización de pertenencia.

Esta forma de responder sobre la modalidad de asistencia es coherente con la percepción sobre el modo de participación de las/ os asistentes: más del $60 \%$ de las/os mismas/os sostuvieron que participaban en carácter de ciudadanas/os independientes. En segundo lugar, las/os manifestantes consideraron que estaban participando como miembros de un movimiento social $(13,42 \%)$.

No obstante, las/os participantes parecen considerarse parte de un colectivo y asumir el carácter político de la movilización. Ante la pregunta de cuán identificadas/os se sentían con la idea "Comparto las consignas de las/os que se están movilizando", un 78,84\% respondió sentirse "totalmente identificada/o". Esta respuesta es consistente con el hecho de haber participado de otras movilizaciones con las mismas consignas como veremos enseguida. En los casos en los que la lógica de la acción conectiva es llevada al extremo, como en el ciclo de cacerolazos 2012-2013 en Argentina (Annunziata y Gold,

C.A.B.A. más 9.916 .715 en los 24 partidos) y una superficie de $3.833 \mathrm{~km} 2$ (203 km2 de C.A.B.A. y 3.630 $\mathrm{km} 2$ de los partidos que la rodean). En la encuesta consideramos separadamente a la C.A.B.A. de los 24 partidos del Gran Buenos Aires. 


\begin{tabular}{|l|c|}
\hline Participa en la movilización como... & Porcentaje \\
\hline Miembro de un partido político & $9,31 \%$ \\
\hline Miembro de un sindicato & $5,75 \%$ \\
\hline $\begin{array}{l}\text { Miembro de una organización } \\
\text { cultural/educativa }\end{array}$ & $9,86 \%$ \\
\hline Miembro de una asociación vecinal & $0,55 \%$ \\
\hline Miembro de un movimiento social & $13,42 \%$ \\
\hline Ciudadana/o independiente & $60,82 \%$ \\
\hline NS/NC & $0,27 \%$ \\
\hline Total & 100 \\
\hline
\end{tabular}

Tabla 1. Carácter de la participación de las/os manifestantes

\begin{tabular}{|l|c|}
\hline Nivel de identificación & Porcentaje \\
\hline Nada identificada/o & $4,12 \%$ \\
\hline Poco identificada/o & $11,26 \%$ \\
\hline Medianamente identificada/o & $39,29 \%$ \\
\hline Bastante identificada/o & $17,58 \%$ \\
\hline Totalmente identificada/o & $26,37 \%$ \\
\hline NS/NC & $1,37 \%$ \\
\hline
\end{tabular}

Tabla 2. Identificación con la frase

"En esta movilización participan mayormente ciudadanas/os independientes"

2018), las/os manifestantes suelen participar con sus propias consignas y carteles, mostrando una gran diversidad en los motivos que las/os impulsan a movilizarse y una coincidencia fuerte solamente en el rechazo o la negatividad. El hecho de que en el 8M las/os manifestantes coincidieran mayormente con las consignas de la movilización habla de una identidad más consolidada.

Llama la atención la brecha entre quienes sostuvieron, como mencionamos arriba, que estaban participando en tanto que ciudadanas/os independientes (un 60,82\%) y la identificación con la expresión "En esta movilización participan mayormente ciudadanas/os independientes".

La mayoría de las/os participantes es dubitativa sobre las pertenencias de las/ os ciudadanos que están movilizándose con ellas/os. Aunque se autodefinen como independientes no creen que las/os demás lo sean en la misma medida.

\subsection{Espontaneidad}

Si bien la participación no fue percibida mayoritariamente como organizada, el nivel de espontaneidad de la protesta puede considerarse como relativamente bajo con respecto a otros acontecimientos que se incluirían en la categoría de "acción conectiva".

Un indicador interesante para evaluar la espontaneidad de la participación es la antelación con la que las/os participantes se enteraron de la convocatoria a la movilización. En aquellas movilizaciones muy espontáneas es habitual que los asistentes se hayan enterado el mismo día, y que incluso sea un efecto contagio, a partir de la información que les llega por diversos medios, lo que las/os impulse a movilizarse. El 8M de 2017 observamos, por el contario, que una importante mayoría de las/os asistentes (el 60\%) se habían enterado de la convocatoria más de 30 días antes de la fecha de la protesta, lo que significa que se habían enterado casi en el momento de su lanzamiento (que fue el 23 de enero de 2017).

La movilización del 3J de 2015 se había lanzado el 11/5 para el 3/6. Ya sólo por este menor lapso de tiempo entre la convocatoria inicial y la movilización puede observarse que fue más espontánea. Pero entre la primera gran movilización y el 8M de 2017 habían ido sucediendo otras protestas en torno a los mismos temas, como mencionamos más arriba: el 3J de 2016y 190 de 2016. De este modo, se había ido consolidando un sujeto. En 


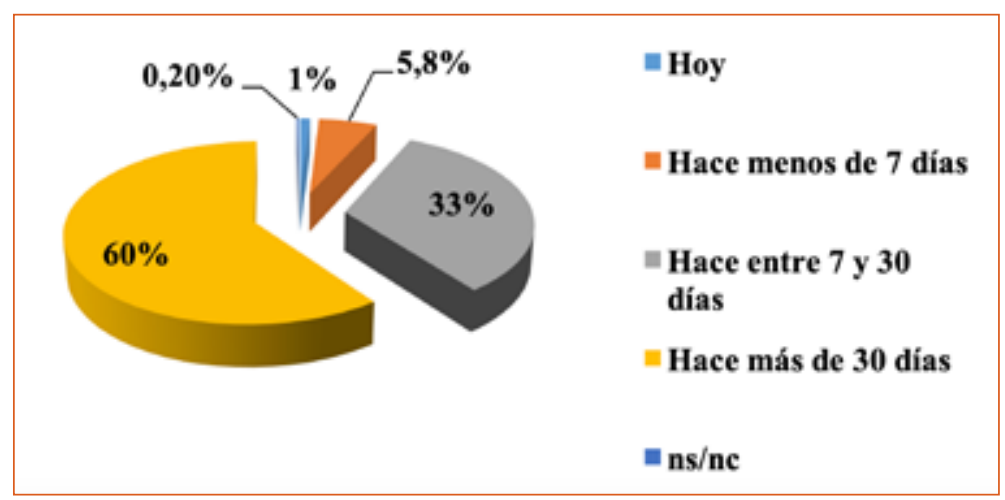

Gráfico 4. Antelación con la que las/os manifestantes supieron de la convocatoria. Fuente: elaboración propia el \#ParolnternacionalDeMujeres del 8 de marzo de 2017, el $88 \%$ de las/os asistentes afirmaba haber participado de movilizaciones anteriormente. Dentro de este grupo, el $62 \%$ sostuvo haber participado de movilizaciones que tenían la misma consigna que aquella a la que estaban asistiendo, lo que refuerza la idea de que se había ido consolidando un sujeto nuevo, en torno a la lucha por los derechos de las mujeres, a partir del 3J de 2015. Las/os asistentes a la movilización se concebían como ciudadanas/os independientes, no particularmente como miembros de organizaciones, pero esto no implicó una despolitización en su forma de participar. Se trata de manifestantes politizadas/os e interpeladas/os por una causa política transversal a los partidos y a las organizaciones.

En efecto, la mayoría de las/os asistentes habían participado de todas las convocatorias en torno al tema desde el 3 de junio de 2015, incluyendo esta misma movilización, la del 3 de junio del año siguiente y el Paro de Mujeres del 19 de octubre de 2016.

\begin{tabular}{|c|c|}
\hline Cantidad de movilizaciones & Porcentaje \\
\hline A una movilización & $18,7 \%$ \\
\hline A dos movilizaciones & $32,0 \%$ \\
\hline A tres movilizaciones & $40,0 \%$ \\
\hline A ninguna & $8,7 \%$ \\
\hline NS/NC & $0,6 \%$ \\
\hline
\end{tabular}

Tabla 3. A cuántas movilizaciones con la misma consigna asistió

\begin{tabular}{|l|c|}
\hline Movilización & Porcentaje \\
\hline 3J 2015 & $6,40 \%$ \\
\hline 3J 2016 & $3,40 \%$ \\
\hline 1902016 & $19,30 \%$ \\
\hline 3J 2015 y 3J 2016 & $4,70 \%$ \\
\hline 3J 2015y 190 2016 & $8,10 \%$ \\
\hline 3J 2016 y 190 2016 & $39,90 \%$ \\
\hline 3J 2015, 3J 2016 y 190 2016 & $8,70 \%$ \\
\hline Ninguna de las anteriores & $0,60 \%$ \\
\hline NS/NC & $100 \%$ \\
\hline Total & \\
\hline
\end{tabular}

Tabla 4. A qué movilizaciones con la misma consigna asistió previamente
Podemos ver en detalle a qué movilizaciones habían asistido las/os participantes en la Tabla 4.

Como vemos, quienes asistieron a tres manifestaciones representan la mayor proporción de las/os encuestadas/os. Entre quienes asistieron a dos manifestaciones previamente, sobresalen quienes habían participado del 3j 2015 y su aniversario en 2016 (siendo en 2017 que asistían al primer paro de mujeres).

Otro indicador sugestivo para pensar la espontaneidad de las movilizaciones es la importancia de quién realiza la convocatoria. Asumimos que cuando una movilización es organizada por un actor identificable con autoridad sobre los participantes, la protesta es menos espontánea; en cambio, cuando no es claro o relevante qué actor lanza el llamado a movilizarse, la espontaneidad es mayor. Es interesante ver que la mayoría de las/os asistentes al $8 \mathrm{M}$ se sintieron identificadas/ os con la idea de que saber quién convoca es importante para decidir si participar o no participar. Un 46,98\% dijeron sentirse totalmente identificadas/os y un $13,74 \%$ 
bastante identificadas/os con esta expresión. Este dato puede tener dos lecturas. En una lógica de acción colectiva clásica, quién convoca a una movilización puede ser determinante porque se sigue el liderazgo de un/a dirigente o de una organización, mientras que en una lógica de acción conectiva en la que la participación ciudadana es más individualizada, podría esperarse que cada quien decida participar más allá de quién sea la figura convocante. Pero también puede entenderse que la lógica de la acción conectiva desdibuje la diferencia entre quien convoca y quien asiste a las manifestaciones, de modo que muchos actores se consideren los convocantes.

\subsection{Redes sociales/medios digitales}

Los medios digitales y/o las redes sociales fueron sin dudas el principal canal por el que las/os asistentes se enteraron de la convocatoria a la movilización, representando el $65 \%$ de los casos (mientras que sólo un 9\% afirmó haberse enterado por la televisión o los diarios, un $14 \%$ por su organización de pertenencia, un $10 \%$ por otros medios y un $2 \%$ NS/NC), como vemos en el Gráfico 5.

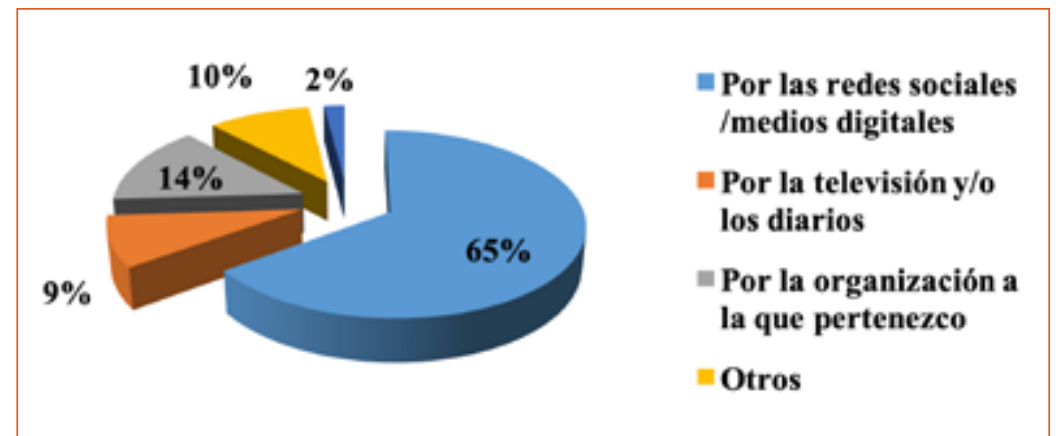

Gráfico 5. Por qué medio se enteró de la movilización

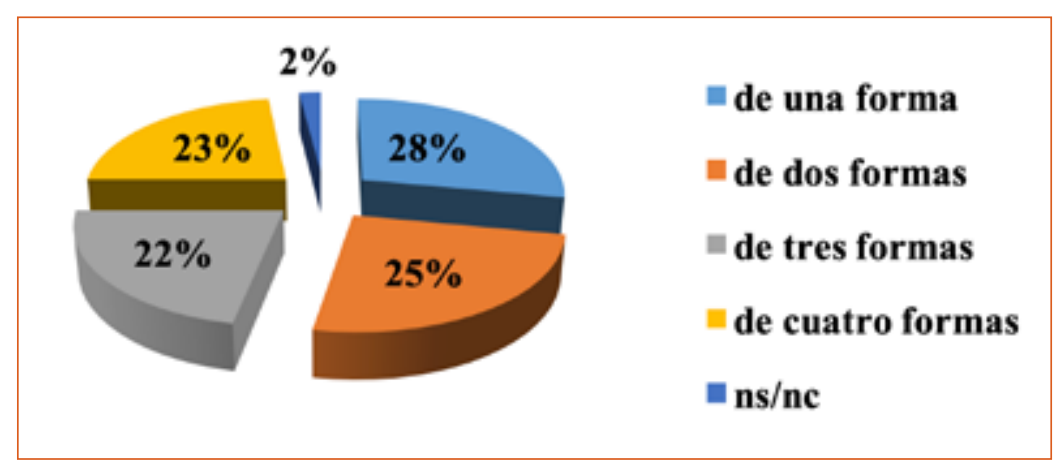

Gráfico 6. De cuántas formas difundió la convocatoria en las redes sociales
Un número incluso levemente mayor de las/os asistentes participaron en la difusión de la movilización por los medios digitales o las redes sociales: el $67 \%$ de las/os encuestadas/ os respondió en este sentido. Este constituye otro elemento importante que refuerza la idea de un público politizado y comprometido:laparticipación activa en la propia difusión de la convocatoria. Este activismo se dio especialmente en los medios digitales ${ }^{11}$.

Si profundizamos en esta dimensión, podemos notar que no se trató de un activismo liviano, como aveces caracteriza la literatura sobre clickactivismo

o slakactivism ${ }^{12}$. Veamos algunas pistas en esta dirección. Una de las preguntas que se hizo a las/os encuestadas/os fue: “ipodría indicarme en cuáles de estas formas participó difundiendo la movilización?". Se trató de una pregunta de respuesta múltiple, lo que

11 Tarullo (2018) subraya que los dirigentes políticos no suelen emplear las herramientas que ofrecen las redes sociales para generar una comunicación interactiva, sino que sus estrategias son más bien "difusionistas". En el caso de las/os participantes de la movilización observamos, en cambio, que la difusión resulta un modo de compromiso activo en la creación del acontecimiento.

12 Los trabajos que se inscriben en la perspectiva del clickactivismo consideran que la participación online constituye una forma superficial, no reflexiva, disminuida y perezosa de participar, y cuestionan la potencialidad que pueda tener este tipo de práctica (Breuer y Farooq, 2012; Butler, 2011; Christensen, 2011; Savazoni y Copello, 2016; Sorj, 2015, 2016; Waisbord, 2015). Generalmente, estos estudios se corresponden con los enfoques pesimistas que mencionamos anteriormente. 


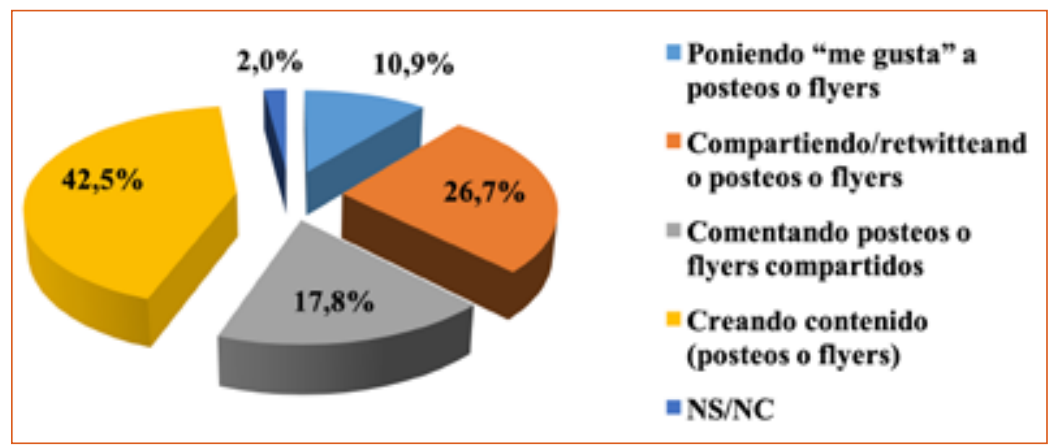

Gráfico 7. De qué formas difundió la convocatoria en las redes sociales nos permitió saber de cuántas formas participaron las/os manifestantes en la difusión de la convocatoria por las redes. En el Gráfico 6 vemos que sólo el $28 \%$ de quienes difundieron por las redes sociales lo hicieron de una única manera, mientras que el restante $70 \%$ lo hizo al menos de dos maneras.

Al considerar el tipo de actividad que llevaron a cabo las/os manifestantes en las redes sociales se destaca un significativo nivel de compromiso. Si construimos una posible escala de implicación en la que 1) "likear" o poner "me gusta" a un contenido creado por otros es el nivel más bajo, 2) pasando por compartir o retwittear el contenido creado por otros (es decir, apropiándose de un contenido y asumiéndolo como propio), 3) luego por comentar posteos compartidos (es decir, agregando algo propio a aquello que se asume) y 4) crear contenido, es claramente el nivel más alto de implicación, se puede evidenciar mejor en qué medida fueron activas/os en la creación del acontecimiento las/os propias/os manifestantes. Crear contenido supone, en efecto, el mayor trabajo y la mayor exposición de sí, que pueden comprenderse como los elementos claves para evaluar la implicación en el ámbito digital (Annunziata, 2019). El Gráfico $7^{13}$ muestra las formas en las que las/os manifestantes colaboraron en la difusión; en los casos en los que las/os encuestadas/os respondieron con más de una opción se tomó aquí aquella que representa el mayor nivel de implicación según nuestra escala. Como se puede observar en este gráfico, sólo el 10,9\% se limitó a poner "me gusta" en publicaciones, y la gran mayoría, en cambio, tuvo un rol mucho más activo. Llama la atención en particular el alto porcentaje de asistentes que dijeron haber "creado contenido" (42,5\%).

Este aspecto no nos habla solamente del nivel de compromiso de las/os manifestantes con la causa de la movilización, sino que también nos permite observar en el \#ParolnternacionalDeMujeres rasgos característicos de las movilizaciones surgidas de las redes en clave de acción conectiva. En primer lugar, la característica señalada desde el comienzo de la conceptualización de internet 2.0: los usuarios son prosumidores (Trejo Delarbre, 2011). En segundo lugar, la tendencia a la horizontalidad del liderazgo (Castells, 2012). Si bien es innegable que existen personas que difunden que son más influyentes que otras y pueden ser concebidas como "nodos" en las redes (Aruguete y Calvo, 2018), lo cierto es que todas/os pueden eventualmente transformarse en importantes polos de difusión y convocatoria. Podemos suponer que en los casos en que una acción colectiva es convocada por una organización, la creación de contenido tiende a disminuir porque hay un mensaje más homogéneo que apoyar y retransmitir. Pero la acción conectiva parece, en cambio, habilitar una mayor libertad y creatividad para convocar a la acción; en el extremo, se desdibuja la diferencia entre quien convoca y quien asiste a una movilización.

13. Tanto el Gráfico 6 como el Gráfico 7 son derivados de la misma pregunta de la encuesta -de respuesta múltiple-: "¿podría indicarme en cuáles de estas formas participó difundiendo la movilización?" En el Gráfico 6 sólo se contabilizan la cantidad de respuestas dadas por las/os participantes, mientras que en el Gráfico 7 se selecciona la respuesta que representa el valor más alto en nuestra escala de implicación. 
Esto último podría ayudarnos a reinterpretar la información que mencionamos en el punto 4.3. sobre la relevancia de quién convoca a la movilización. En un contexto de tendencia a la acción conectiva podemos notar que se produce una confluencia y borramiento de las fronteras entre convocantes y asistentes. Si quien asiste a una movilización es también quien convoca, entonces quien convoca vuelve a tener centralidad, pero no necesariamente por la existencia de vínculos verticales u orgánicos entre las/os participantes, sino por la auto-referencialidad de este tipo de acción.

Una brecha significativa puede verse entre la percepción del rol de las redes sociales en la movilización y la proporción de participantes que conocieron la convocatoria a través de las redes y que afirmaron haber sido activas/os en la difusión de diferentes maneras.

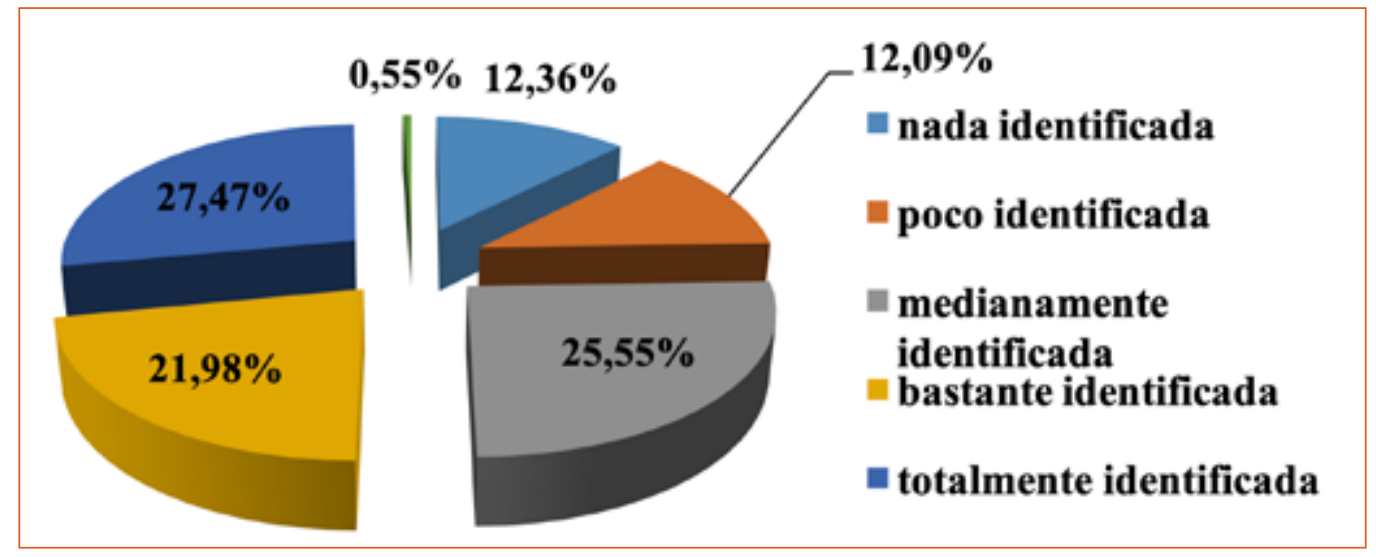

Gráfico 8. Identificación con la frase

"Sin las redes no sería posible un acontecimiento con éste"

Si bien la mayoría le otorga a las redes sociales una influencia muy importante en la movilización (49,45\% se sienten "totalmente" o "bastante" identificadas/os), como vemos en el Gráfico 8, este dato contrasta con el rol mayor que efectivamente tuvieron como canal de difusión para las mismas personas; recordemos que el $65 \%$ de las/os encuestadas/os respondió haberse enterado de la movilización por las redes sociales y el $67 \%$ respondió que participó activamente en la difusión por este mismo medio. Es posible conjeturar que, al tratarse de una población especialmente consciente de las consignas, del carácter político de la lucha y del esfuerzo organizativo del movimiento de mujeres, tenga una tendencia a subestimar el rol de las redes sociales como si fuera competitivo con el peso propio del movimiento social o sus banderas de larga data.

\subsection{Visión de la política}

La percepción de pertenencia a un colectivo con una consigna clara fue de la mano con el reconocimiento del carácter político de la protesta por parte de las/os manifestantes. En efecto, un $69,78 \%$ respondió sentirse totalmente identificada/o con la expresión "Al venir a la movilización estoy haciendo política".

Podríamos pensar a primera vista que se trata de una politización no tradicional o no ligada a la política de partidos. Aunque no por una gran diferencia, la mayoría de las/os participantes (un 32,97\%) se sintieron identificadas/os con la idea "Esta es una movilización a-partidaria". Quienes participan reconocen que están haciendo política cuando se manifiestan, pero sienten que están contribuyendo con una manifestación 


\begin{tabular}{|l|c|}
\hline Nivel de identificación & Porcentaje \\
\hline Nada identificada/o & $14,56 \%$ \\
\hline Poco identificada/o & $4,12 \%$ \\
\hline Medianamente identificada/o & $5,22 \%$ \\
\hline Bastante identificada/o & $6,04 \%$ \\
\hline Totalmente identificada/o & $69,78 \%$ \\
\hline NS/NC & $0,27 \%$ \\
\hline
\end{tabular}

Tabla 5. Nivel de identificación con la frase "Al venir a la movilización estoy haciendo política" a-partidaria. No obstante, lo cierto es que la percepción que parece haber predominado mayormente es la de una movilización trans-partidaria, es decir, en la que los partidos políticos se ven involucrados, pero no existe un sesgo que otorgue a alguno de ellos un rol especial en la convocatoria o en la participación. Ante la pregunta por la identificación con la expresión "En esta movilización participan diferentes partidos políticos" un 73,35\% respondió sentirse totalmente identificada/o. Esta respuesta es consecuente con el hecho de que la mayoría de las/os manifestantes se sentían identificados con la frase "Me parece bien que las/os políticos/as participen en movilizaciones ciudadanas" (un 55,22\%).

\subsection{Negatividad}

En la movilización \#NiUnaMenos del 3 de junio de 2015, las impulsoras subrayaban que se había podido reunir a quienes estaban a favor de la despenalización del aborto y en contra del mal llamado "piropo callejero" por considerarlo el principio de una cadena de violencias contra las mujeres, con representantes de la Iglesia católica y familiares de víctimas que se movilizaban para frenar los femicidios, pero no compartían todas las posibles demandas feministas (Annunziata et al., 2016). En el \#ParolnternacionalDeMujeres vemos que este aspecto típico de la acción conectiva según nuestra interpretación estuvo más matizado. Sin embargo, la negatividad fue de todos modos el rasgo onmipresente. Casi el 90\% de las/os manifestantes se sintieron totalmente identificadas/os con la expresión "Salgo a la calle para decir ‘ßBasta!"', como se puede observar en el Gráfico 9.

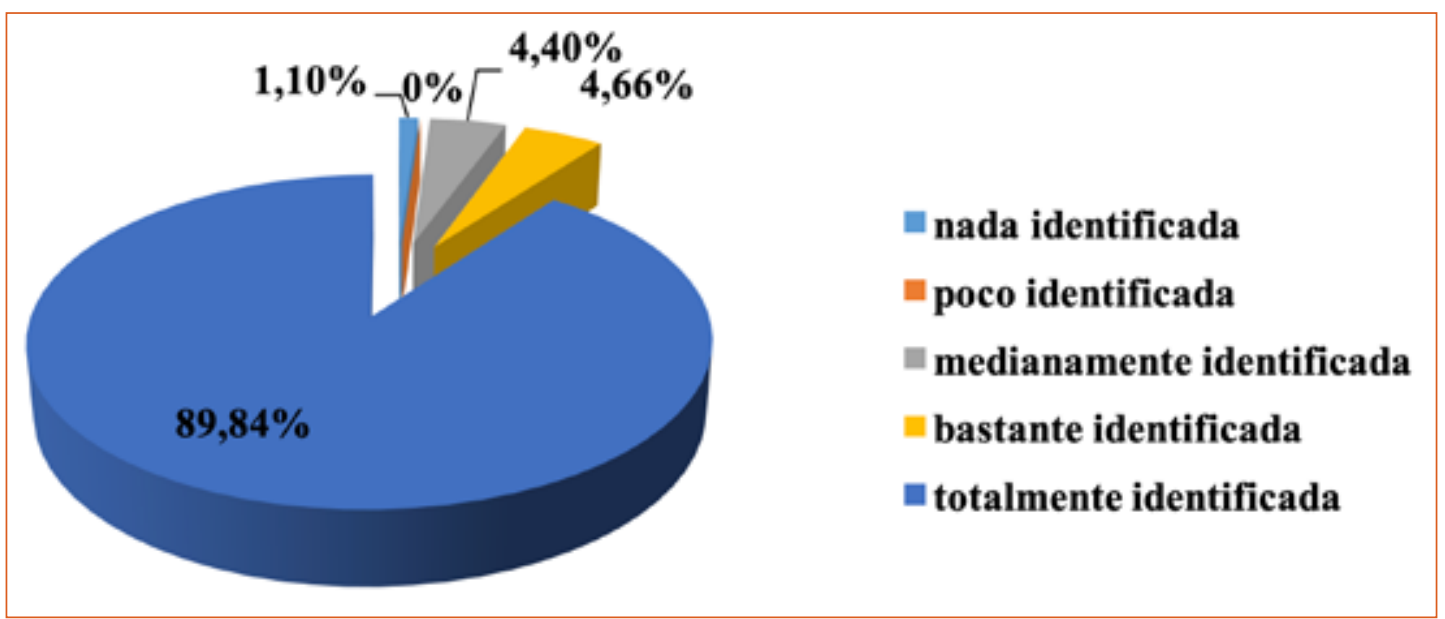

Gráfico 9. Identificación con la frase “Salgo a la calle para decir ‘Basta!’

La negatividad se observa con claridad cuando se verifica el desfasaje entre quienes se movilizan para rechazar, para decir “¡No!" o “iBasta!”, y quienes esperan cambiar o modificar determinadas políticas en un sentido positivo, sosteniendo alguna agenda o proyecto o esperando impactos concretos de su acción. En nuestro caso, mientras que casi el 90\% expresaba un rechazo ("totalmente identificada/o"), cerca del 70\% de 


\begin{tabular}{|l|c|}
\hline Nivel de identificación & Porcentaje \\
\hline Nada identificada/o & $15,66 \%$ \\
\hline Poco identificada/o & $14,29 \%$ \\
\hline Medianamente identificada/o & $23,63 \%$ \\
\hline Bastante identificada/o & $9,34 \%$ \\
\hline Totalmente identificada/o & $36,26 \%$ \\
\hline NS/NC & $0,82 \%$ \\
\hline
\end{tabular}

Tabla 6. Identificación con la frase "La forma más efectiva de participar en democracia es el voto"

las/os participantes se sentían totalmente identificadas/os con la frase "Salgo a la calle para afectar el rumbo de las políticas". Este desfasaje ha sido probablemente mayor en otras movilizaciones recientes convocadas a través de las redes sociales en Argentina y en el mundo. Sin embargo, cabe destacar que la experiencia del \#ParolnternacionalDeMujeres constituye una evidencia más del peso de la negatividad en la política contemporánea.

Como dijimos más arriba, no encontramos entre las/os manifestantes un grado alto de rechazo a la política o la clase política en general, de modo que esta negatividad predominante no se traduce en un carácter anti-político de la movilización como puede suceder en algunos casos extremos de acción conectiva. En todo caso, notamos que las/os manifestantes apuestan a diferentes formas de hacer política: aunque consideran que la manifestación tiene un carácter político y trans-partidario, estiman que participan como ciudadanas/os independientes y de manera individual más que organizada. Esta politización no tradicional es consistente también con la evaluación del voto como modalidad más efectiva de participación democrática. Una leve mayoría se siente totalmente identificada/o con la expresión "La forma más efectiva de participar en democracia es el voto", pero también es significativa la proporción de aquellas/os que no se sienten nada o se siente poco identificadas/os con esta afirmación.

\section{Discusión}

Si consideramos ahora las diferentes dimensiones que derivamos de la teoría de la acción conectiva y de los aportes de otros autores contemporáneos podemos responder a nuestra pregunta de investigación observando que el caso del 8M corresponde a un patrón híbrido de este tipo de acción.

Con respecto a la participación de organizaciones, vimos que, aunque su presencia fue muy visible durante la movilización, sólo el $21 \%$ dijo haber asistido con su organización de pertenencia; al mismo tiempo, más del $60 \%$ de las/os participantes asistieron en calidad de "ciudadanas/os independientes". Si estos elementos nos hablan de un bajo grado organizativo, es decir, se orientan a la acción conectiva más pura, debemos recordar que también casi un $80 \%$ de las/os manifestantes se sentían totalmente identificadas/os con la idea de que compartían las consignas de quienes se estaban movilizando (y habían participado mayoritariamente de movilizaciones previas con consignas similares), de modo que podemos notar la consolidación de una identidad en torno a la causa de la lucha por los derechos de las mujeres, más allá del formato organizativo.

Un bajo grado de adscripción a organizaciones que va en la línea de la acción conectiva pura se compensa con una espontaneidad baja que iría en la dirección contraria. Recordemos que el $60 \%$ supo con más de un mes de anticipación de la existencia de la convocatoria y existieron encuentros preparatorios de colectivos de mujeres y de género en muchos lugares del país. 
Las redes sociales y los medios digitales fueron el principal canal de difusión de la convocatoria a la movilización, pero al mismo tiempo las/os manifestantes afirmaron haber participado activamente en la difusión, no sólo expresando "me gusta", compartiendo y comentando, sino, especialmente, creando contenidos propios. En esta dimensión el 8M se acercó más a lo esperado para la acción conectiva pura.

Con respecto a la visión de la política, recordemos que el 70\% de las/os manifestantes se sintió totalmente identificada/o con la frase: "Al venir a la movilización estoy haciendo política". Este reconocimiento del carácter político y trans-partidario de la movilización no cumpliría con la expectativa para la acción conectiva más extrema.

Finalmente, la negatividad pareció tener un rol estructurante en la movilización, en la medida en que casi el $90 \%$ de las/os encuestadas/os se sintió totalmente identificada/o la expresión “Salgo a la calle para decir '¡Basta!"”

Como sintetizamos en la Tabla 7, en tres de las dimensiones analíticas que establecimos la experiencia del 8M según la percepción de las/os manifestantes parece haber ido en la dirección esperada para una acción conectiva pura, mientras que no fue así en las otras dos dimensiones, lo que nos lleva a sostener que el acontecimiento se inscribió más bien en una lógica híbrida de acción conectiva.

\begin{tabular}{l|c|c|}
\hline \multicolumn{1}{l}{$\begin{array}{l}\text { Dimensiones de la acción } \\
\text { conectiva }\end{array}$} & $\begin{array}{c}\text { Resultado esperado para la } \\
\text { acción conectiva pura }\end{array}$ & $\begin{array}{c}\text { 8M según la percepción de } \\
\text { las/os participantes }\end{array}$ \\
\hline Organización & Baja & Baja \\
\hline Espontaneidad & Alta & Baja \\
\hline Activismo en redes sociales & Alta & Alta \\
\hline Politización & Baja & Alta \\
\hline Negatividad & Alta & Alta \\
\hline
\end{tabular}

Tabla 7. Dimensiones de la acción conectiva y resultados del 8M 2017

\section{Conclusión}

En estas páginas hemos presentado la información producto del relevamiento realizado en la Ciudad de Buenos Aires en el \#ParolnternacionalDeMujeres del 8 de marzo de 2017, conocido también como 8M. De acuerdo con la percepción de las/os participantes hemos llegado a concluir que se trató de una experiencia que puede ser leída en clave de acción conectiva híbrida. De hecho, se observó que las/os manifestantes no pusieron en primer lugar su participación como miembros de organizaciones, fueron cocreadores activos del acontecimiento en las redes y los medios digitales y consideraron fundamental el carácter de rechazo a la situación actual respecto de la violencia contra las mujeres, pero el grado de espontaneidad de la movilización fue relativamente bajo y el reconocimiento del carácter político y trans-partidario de la misma fue alto.

Aunque se centró los datos reunidos en el 8M de 2017, la investigación también permitió ver cómo fue cambiando la fisonomía de las movilizaciones entre el 3 de junio de 2015 y la irrupción de \#NiUnaMenos y el acontecimiento del \#ParolnternacionalDeMujeres casi dos años después. Si observamos globalmente las manifestaciones del 3j y del 8M podemos notar que hubo un desplazamiento o una transformación en los sujetos y en la lógica de las mismas. La primera representó la emergencia de un sujeto que era 
distinto al movimiento social feminista. Esta protesta, con la magnitud que adquirió, no podría haber sido organizada por organizaciones feministas. Pero luego del impacto que tuvo el 3J y a medida que se fueron sucediendo nuevas movilizaciones, se llegaba al año 2017 con un nivel más sólido de organización e incluso de inscripción en redes internacionales, y habiendo orientado las consignas, los símbolos y el discurso hacia registros más feministas. Estos cambios invitan a proseguir la investigación para poder comparar el $8 \mathrm{M}$ con otras protestas en torno al mismo tema, y demostrar así de un modo más sistemático los ciclos por lo que pueden moverse las movilizaciones ciudadanas contemporáneas, entre formas más o menos puras de acción conectiva e incluso de acción colectiva clásica. Recordemos que Bennet y Segerberg (2012) asumían que dentro de un mismo ciclo es posible que vaya cambiando el tipo de acción. Retomando su tipología, pudimos ver que el movimiento \#NiUnaMenos en Argentina se pasó de un primer momento de acción conectiva pura a un momento de acción conectiva híbrida.

Varias líneas se abren a partir de esta primera aproximación descriptiva a la lógica de la acción conectiva en protestas concretas. Comparar el 8M con otras manifestaciones surgidas de las redes sociales o medios digitales, pero sobre temas y con consignas diferentes sería el camino para construir un nuevo andamiaje teórico capaz de comprender las movilizaciones ciudadanas contemporáneas que ya no pueden ser capturadas con los conceptos tradicionales.

Otro aspecto para profundizar es la comparación entre los datos recolectados y el producto de un análisis visual (Doerr, Mattoni y Teune, 2013) de las manifestaciones. Uno de los elementos que Ilaman la atención de los hallazgos de este estudio es el contraste entre la percepción de las/os manifestantes de su propia participación en tanto que ciudadanas/os independientes que conocen la convocatoria por los medios digitales y no por sus organizaciones y que sostienen haber ido solas/os o con amigas/ os antes que con sus colectivos de pertenencia, por un lado, y la gran cantidad de organizaciones identificables por sus banderas y pancartas que podían verse en la movilización, por el otro. Si algo estuvo muy presente en la imagen que transmitió el $8 \mathrm{M}$ fueron los símbolos de la pertenencia a organizaciones, colectivos, partidos y sindicatos. El pañuelo verde, por poner un solo ejemplo, símbolo de la lucha por la conquista del derecho al aborto seguro, legal y gratuito, originalmente distintivo de la Campaña Nacional, tuvo una presencia muy fuerte en el 8M y se popularizaría aún más en las movilizaciones posteriores. ¿Qué significación tiene este contraste entre la autopercepción individualizada de la participación y la manifiesta participación colectiva? Hay que considerar también que, en las movilizaciones ciudadanas contemporáneas, los carteles "hechos en casa" de manera individual y por iniciativa espontánea de quienes participan conviven cada vez más con las pancartas y banderas de sindicatos, partidos u organizaciones (Annunziata, 2016), lo que cristaliza el carácter de expresión personalizada que tiene la acción conectiva.

Por último, sería interesante profundizar en las formas de activismo digital en las que se involucran las/os manifestantes y poner a prueba la escala de implicación que sugerimos en este artículo para las redes sociales, de modo de contribuir a la discusión sobre el clickactivismo. ¿Cuáles son las formas de creación de contenido con las que se expresan las/os manifestantes en las redes? ¿En qué medida esta participación es un compromiso en términos de exposición de sí y de esfuerzo invertido? ¿Qué conexión encuentran entre esa forma de participar y la que se desarrolla en las manifestaciones 
callejeras? La variedad de interrogantes que permanecen inexplorados y convocan a nuevas investigaciones es una prueba de la productividad de un campo de estudios incipiente -el de las movilizaciones ciudadanas y su vínculo con las redes sociales- que debe combinar enfoques diversos para iluminar la especificidad de estos fenómenos políticos novedosos.

\section{Referencias}

Annunziata, R. (2016): “Entre la gestión y la negatividad. Aportes para una conceptualización de las nuevas formas no electorales de participación". En Mayorga, F. (comp): Elecciones y legitimidad democrática en América Latina. La Paz: CLACSOPlural, pp. 313-342.

Annunziata, R. (2019): “'Poner el cuerpo'. La contingencia del vínculo entre formatos de involucramiento y efectos en las formas de participación en la era digital". En Dabène, O. y Launay Gama, C. (comps): Los efectos de los procesos participativos en la acción pública. Buenos Aires: Teseo, pp. 51-90.

Annunziata, R., Arpini, E., Gold, T. y Zeifer, B. (2016): “Argentina”. En Sorj, B. y Fausto, S. (comps.): Activismo político en tiempos de Internet. Sao Paulo: Plataforma Democrática, pp. 37-112.

Annunziata, R. y Gold, T. (2018): "Manifestaciones ciudadanas en la era digital. El ciclo de cacerolazos (2012-2013) y la movilización \#NiUnaMenos (2015) en Argentina", en Desarrollo Económico. Revista de Ciencias Sociales, IDES, vol. 57, n²33, enero-abril de 2018, pp. 363-388.

Aruguete, N., y Calvo, E. (2018): "Time to \#protest: Selective exposure, cascading activation, and framing in social media", en Journal of Communication, vol. 68, $\mathrm{n}^{\circ} \mathrm{3}, \mathrm{pp}$. 480-502.

Bennet, L. W. y Segerberg, A. (2012): "The Logic of Connective Action", en Information, Communication \& Society, vol. $15, n^{\circ} 5$, pp. 739-768.

Bennet, L. W. y Segerberg, A. (2013): The Logic of Connective Action. Digital Media and the Personalization of Contentious Politics. Cambridge: Cambridge University Press.

Breuer, A. y Farooq, B. (2012): “Online Political Participation: Slacktivism or Efficiency Increased Activism? Evidence from the Brazilian Ficha Limpa Campaign". Comunicación presentada en ICA Annual Conference. San Francisco, 24 - 28 de mayo de 2012.

Butler, M. (2011): “Clicktivism, Slacktivism, or 'Real' Activism. Cultural Codes of American Activism in the Internet Era". Tesis presentada para el Master of Communication, University of Colorado.

Castells, M. (2012): Redes de esperanza e indignación. Madrid: Alianza Editorial

Christensen, H. S. (2011): "Political activities on the Internet: Slacktivism or political participation by other means?", en First Monday, vol. 16, n² - 7 de febrero de 2011. Disponible en: http://firstmonday.org/ojs/index.php/fm/article/view/3336/2767

Diani, M. (2011): "Networks and Internet into perspective", en Swiss Political Science Review, vol. 17, $\mathrm{n}^{\circ} 4$, pp. 469-474.

Diani, M. (2015): “Revisando el concepto de movimiento social”, en Encrucijadas. Revista Crítica de Ciencias Sociales, n 9, pp. 1-16.

Doerr, N., Mattoni, A. y Teune, S. (2013): Advances in the Visual Analysis of Social Movements. Bingley: Emerald 
Fernández Rincón, A. R. (2019): “Artivismo y co-creación: la comunicación digital en la huelga feminista del 8M", en Dígitos. Revista de comunicación digital, n5 5, pp. 56-74.

Gago, V. (2018): "\#Nosotras paramos": notas hacia una teoría política de la huelga feminista". En V.V.A.A: 8M Constelación feminista. ¿Cuál es tu huelga? ¿Cuál es tu lucha? Buenos Aires: Tinta Limón, pp. 7-23.

Ghonim, W. (2013): Revolution 2.0. The power of the people is stronger than the people in power. New York: Houghton Mifflin Harcourt.

Iglesias, M. (2017): “En su día, ellas ganaron la calle para ponerle un freno a la cultura machista", en Clarín, 09 de marzo de 2017. Disponible en: https://www.clarin.com/ sociedad/dia-ganaron-calle-ponerle-freno-cultura-machista_0_Byf9aM05g.html (Consulta: 01/04/2020).

Klandermans, B., van Stekelenburg, J. and Walgrave, S. (2014): “Comparing Street Demonstrations", en International Sociology, vol. 29, n 6, pp. 493-503.

Kowalska, D. (2018). "The Fourth Wave of American Feminism: Ideas, Activism, Social Media", Tesis de Maestría, University of Warsaw. DOI: 10.13140/RG.2.2.25482.36808.

Laudano, Claudia (2018): “\#8M Paro internacional de mujeres. Reflexiones en torno a la apropiación feminista de TIC". En Lago Martínez, S., Alvarez, A., Gendler, M. y Méndez, A. (ed.): Acerca de la apropiación de tecnologías. Teoría, estudios y debates. Rada Tilly: Del gato gris, pp. 121-130.

Natalucci, A. y Rey, J. (2018): “¿Una nueva oleada feminista? Agendas de género, repertorios de acción y colectivos de mujeres (Argentina, 2015-2018)", en Revista de Estudios Políticos y Estratégicos, vol. 6, n² 2, pp. 14-34.

NiUna Menos (2017a): “Llamamiento al Paro Internacional de Mujeres - 8 de marzo 2017 . Facebook [en línea]. Disponible en: https://www.facebook.com/notes/ni-una-menos/ Ilamamiento-al-paro-internacional-de-mujeres-8-de-marzo-2017/588055324718987/ (Consulta: 11/04/2020).

Ni Una Menos (2017b): “¿Cómo se fue tejiendo el Paro Internacional de Mujeres 8M?", en Tiempo Argentino, 15 de febrero de 2017. Disponible en: https://www.tiempoar. com.ar/nota/como-se-fue-tejiendo-el-paro-internacional-de-mujeres-8m (Consulta: 01/04/2020).

Rodríguez, Paula (2015): \#NiUnaMenos. Buenos Aires: Planeta.

Rosanvallon, P. (2007): La contrademocracia. La política en la era de la desconfianza. Buenos Aires: Manantial.

Rosanvallon, P. (2012): La sociedad de iguales. Buenos Aires: Manantial.

Savazoni, R. y Copello, K. (2016): "Brasil". En Sorj, B. y Fausto, S. (comps.): Activismo político en tiempos de internet. San Pablo: Plataforma Democrática.

Somma, N. M.; Rossi, F. M. y Donoso, S. (2019): “The Attachment of Demonstrators to Institutional Politics: Comparing LGBTIQ Pride Marches in Argentina and Chile", en Bulletin of Latin American Research, Society for Latin American Studies, DOI:10.1111/ blar.12956

Sorj, B. (2015): “On-line/off-line: la nueva onda de la sociedad civil y la transformación de la esfera pública". En Sorj, B. y Fausto, S. (org.): Internet y movilizaciones sociales: transformaciones del espacio público y de la sociedad civil. San Pablo: Plataforma Democrática, Fundación IFHC.

Sorj, B. (2016): “Online/Offline: el nuevo tejido del activismo político”. En Sorj, B. y 
Fausto, S. (comps.): Activismo político en tiempos de internet. San Pablo: Plataforma Democrática.

Stekelenburg, J., Walgrave, S., Klandermans, B. y Joris, V. (2012): “Contextualizing Contestation: Framework, Design, and Data", en Mobilization, vol. 17, n³, pp. 249262.

Tarullo, R. (2018): “El uso estratégico de la interacción en la comunicación de los políticos argentinos", en Global Media Journal México, vol. 15, n²9, julio - diciembre, pp. 152178.

Trejo Delarbre, R. (2011): “¿Hacia una política 2.0? Potencialidades y límites de la red de redes", en Nueva Sociedad, n²35, septiembre-octubre de 2011, pp. 62-73.

Trott, V. (2018): “Connected feminists: foregrounding the interpersonal in connective action" en Australian Journal of Political Science, vol. 53, n¹, pp. 116-129.

Waisbord, S. (2015): “El optimismo digi-activista y sus problemas”. En Amado, A. y Rincón, O. (comps.): La comunicación en mutación. Bogotá: Friedrich Ebert Stiftung.

Welp, Y. (2015): “Cuando todo lo sólido se desvanece en twitter. Análisis del movimiento social \#Yosoy132 (México 2012)", en PostData. Revista de Reflexión y Análisis Político, vol. 20, $n^{\circ} 2$, pp. 417-439.

Weyland, K. (2012): "The Arab Spring: Why the Surprising Similarities with the Revolutionary Wave of 1848?", en Perspectives on Politics, vol. 10, n4, pp. 917-934.

Zeifer, B. (2017): "Cómo hacer un análisis político y discursivo de un hashtag. El caso de \#NiUnaMenos". Comunicación presentada en las IX Jornadas de Jóvenes Investigadores. Instituto de Investigaciones Gino Germani, Universidad de Buenos Aires, 1-3/11/2017. 
